\title{
ARTIKELEN
}

\section{Toepassing van de pre-pack in Curaçao: wat zijn de spelregels?}

\author{
Mr. R.M. Bottse $e^{*}$
}

\section{Inleiding}

De doorstart van de naamloze vennootschap Curaçaose Dok Maatschappij (hierna: CDM) werd voorafgegaan door een pre-packprocedure. De pre-packprocedure was de deus ex machina die voor de renaissance van CDM heeft gezorgd, aldus de strekking van een artikel met de kop 'Dok gered' in het Antilliaans Dagblad van 2 februari 2017.

Sinds 2012 wordt de pre-pack in de Nederlandse rechtspraktijk regelmatig toegepast. De pre-pack betreft een (niet wettelijk geregeld) instrument waarbij vóór een faillissement in stilte de verkoop van de activa van een onderneming wordt voorbereid. Op verzoek van de schuldenaar wordt aan de rechtbank verzocht om een beoogd curator aan te wijzen die in overleg met de schuldenaar de activatransactie voorbereidt. Na het uitspreken van het faillissement, waarmee de pre-packfase eindigt, kan de inmiddels officieel aangestelde curator direct een doorstart bewerkstelligen via een activatransactie met de geselecteerde kandidaat-koper van de activa. De gedachte achter een pre-packprocedure is dat onzekerheid en een breuk in de continuiteit van de onderneming wordt voorkomen alsmede dat waardeen werkgelegenheidsverlies zo beperkt mogelijk worden gehouden. ${ }^{1}$

Veel rechtbanken in Nederland zijn, ondanks het ontbreken van een wettelijke basis, de afgelopen jaren regelmatig bereid geweest om verzoeken tot toepassing van de pre-pack te honoreren. ${ }^{2}$ In Nederland is thans een wet in voorbereiding, de Wet continuiteit ondernemingen I (hierna: WCO I), die de pre-pack een wettelijke basis moet geven. ${ }^{3}$ Een arrest van het Hof van Justitie van de Europese Unie van 22 juni 2017 doet echter de vraag rijzen of de WCO I op dit moment nog enig bestaansrecht heeft. ${ }^{4}$

Het Europese Hof van Justitie oordeelde namelijk dat Richtlijn 2001/23/EG van de Raad van 12 maart 2001 inzake de onderlinge aanpassing van de wetgevingen der lidstaten betreffende het behoud van de rechten van de werknemers bij overgang van ondernemingen, vestigingen of onderdelen van ondernemingen of vestigingen (hierna: de Richtlijn) van toepassing is in een situatie waarin de overgang van een onderneming plaatsvindt na

* Mr. R.M. Bottse is advocaat bij HBN Law.

1 Zie o.a. N.W.A. Tollenaar, 'Faillissementsrechters van Nederland: geef ons de pre-pack!', Tijdschrift voor Insolventierecht 2011/23.

2 Naar verluidt zijn de afgelopen jaren acht van de elf rechtbanken in Nederland bereid gebleken om mee te werken aan een pre-pack.

3 De WCO I ligt thans voor goedkeuring bij de Eerste Kamer.

4 HvJ EU 22 juni 2017, C-126/16, ECLI:EU:C:2017:489 (FNV/Smallsteps B.V.). 
een faillietverklaring in de context van een daarvóór voorbereide en onmiddellijk erna uitgevoerde pre-pack.

De door de Richtlijn geboden werknemersbescherming is in Nederland geïmplementeerd in artikel 7:662 e.v. BW. Het gevolg van de uitspraak van het Europese Hof van Justitie zou kunnen zijn dat alle werknemers ten tijde van de doorstart in dienst zijn getreden bij de doorstarter. Hierdoor lijkt de pre-pack in Nederland enkel nog geschikt voor de gevallen waarbij het niet bezwaarlijk wordt geacht dat de doorstarter het gehele personeelsbestand overneemt. ${ }^{5}$ Helaas is in de meeste gevallen een afslanking van het personeelsbestand zonder hoge afvloeiingskosten een noodzakelijke voorwaarde voor een geslaagde doorstart, te weten een doorstart met de hoogste opbrengst en met behoud van de meeste werkgelegenheid.

De beslissing van het Europese Hof van Justitie lijkt overigens niet belemmerend te werken voor de ontwikkeling van de pre-pack in Curaçao. Bij gebrek aan een wettelijke basis kan nochtans ervan worden uitgegaan dat de regeling van het behoud van werknemersrechten bij overgang van onderneming niet geldt in Curaçao (en evenmin in Sint Maarten en de BES-eilanden). ${ }^{6}$ Dit neemt niet weg dat indien een faillissement als enig doel heeft om op een goedkope wijze van personeel en personeelslasten af te komen, een faillissementsaanvraag misbruik van bevoegdheid kan opleveren.

Het gerecht in Curaçao heeft in juni 2017, onder verwijzing naar de pre-pack van CDM, aan de op Curaçao actieve curatoren medegedeeld dat zij niet bij voorbaat afwijzend staat tegenover een pre-packprocedure. Een dergelijke positieve instelling van het gerecht valt te loven, maar het verdient aanbeveling om spelregels voor toepassing van de pre-pack in het leven te roepen en bekend te maken.

Voor de praktijk is het van belang dat schuldenaren weten welke gevallen in aanmerking kunnen komen voor toepassing van de pre-pack en welke informatie bij een verzoek tot toepassing van de pre-pack dient te worden overgelegd. Daarnaast dient duidelijkheid te bestaan over de rol van de beoogd curator en hoe de werkzaamheden van de beoogd curator tijdens de pre-packfase en het verkoopproces van de activa achteraf transparant wordt voor schuldeisers en andere belanghebbenden. Deze bijdrage is een pleidooi om duidelijke spelregels te formuleren (i.e. pre-packrichtlijnen) voor toepassing van de pre-pack in Curaçao.

\section{Enkele opmerkingen vooraf}

Ik ga ervan uit dat in Curaçao geen plannen bestaan voor een herijking van het Faillissementsbesluit 1931 (hierna: FB) in het kader waarvan aan de pre-pack een wettelijke basis zal worden gegeven. Dit lijkt logisch, omdat naar verwachting de fascinatie voor de pre-

5 Uit het verslag d.d. 9 februari 2017 van de curator over de pre-packfase in het faillissement van CDM, blijkt overigens dat de doorstart van CDM niet gepaard is gegaan met afslanking van het personeelsbestand.

6 Zie Gem. Hof van Aruba, Curaçao, Sint Maarten en van Bonaire, Sint Eustatius en Saba 31 augustus 2012, EJ 8/2012 - H89/12, ECLI:NL:OGHACMB:2012:BX8562.

7 Zie HR 29 juni 2001, ECLI:NL:HR:2001:AB2388, Jurisprudentie Onderneming \& Recht 2001/169. 
pack in Curaçao aanmerkelijk minder groot zal zijn dan in Nederland. Deze bijdrage is daarom geschreven tegen de achtergrond dat toekomstige pre-packverzoeken in Curaçao, anders dan in Nederland, niet vooruitlopend op de mogelijke invoering van een wettelijke regeling door het gerecht zullen worden ingewilligd en dat in Curaçao de pre-pack een buitenwettelijk fenomeen zal blijven.

\section{Wanneer is er aanleiding voor de aanwijzing van een beoogd curator?}

Toepassing van de pre-pack is een buitenwettelijk fenomeen en dient daarom beperkt te blijven tot bijzondere gevallen. Een aanwijzing van een beoogd curator dient slechts plaats te vinden bij schuldenaren die in financiële moeilijkheden verkeren, maar toch overlevingskansen hebben. Onder een in 'financiële moeilijkheden' verkerende schuldenaar dient te worden verstaan een schuldenaar die in een situatie dreigt te geraken waarin hij met het betalen van zijn schulden niet kan voortgaan.

Een schuldenaar dient dus niet feitelijk al in de toestand te verkeren dat hij is opgehouden met betalen. Met andere woorden, voor een pre-pack is alleen plaats als de schuldenaar nog in staat is om tijdens de pre-packfase de lopende en nieuwe betalingsverplichtingen te voldoen. Hierbij kan het dus ook gaan om verplichtingen jegens contractspartijen onder duurovereenkomsten, die geen weet hebben van de pre-pack en tijdens de pre-packfase doorgaan met het leveren van hun prestaties aan de schuldenaar, en daarbij dus onbewust het risico lopen dat hun vorderingen deels of volledig onbetaald blijven. Dat hierin een risico voor de bestuurder van de schuldenaar schuilt (en wellicht ook voor een beoogd curator die er niet op heeft toegezien dat de schuldenaar tijdens pre-packfase verplichtingen aangaat die niet kunnen worden voldaan), wordt geillustreerd door het Beklamelarrest. ${ }^{8}$ Volgens Beklamel is een bestuurder van een vennootschap persoonlijk aansprakelijk indien hij verplichtingen aangaat waarvan hij weet of moet weten dat de vennootschap die niet kan nakomen en hij geen verhaal biedt voor de daardoor veroorzaakte schade. Beklamel laat ik hier verder onbesproken, maar mijns inziens kunnen aansprakelijkheidsrisico's op de loer liggen indien, ondanks een geslaagde pre-pack, bepaalde crediteuren niet volledig zijn betaald voor tijdens de pre-packfase geleverde diensten.

Daarnaast is er het probleem met het betalen van bepaalde crediteuren in het zicht van insolventie indien er niet voldoende middelen aanwezig zijn om alle schuldeisers te voldoen (i.e. selectieve betaling). Voor een aantal crediteuren, zoals werknemers, is goed verdedigbaar dat zonder hen de onderneming tijdens de pre-packfase niet voortgezet kan worden en dat het wel betalen van hun vorderingen tijdens de pre-packfase niet per se onrechtmatig is ten opzichte van andere crediteuren. Maar lang niet altijd zal dit duidelijk zijn en lopen de bestuurders een aansprakelijkheidsrisico wegens selectieve betaling. ${ }^{9}$

Een beoogd curator dient bij de inwilliging van een pre-packverzoek daarom als mandaat mee te krijgen dat hij erop moet toezien dat de schuldenaar gedurende de pre-packfase zijn verplichtingen jegens al zijn crediteuren kan nakomen. Dit mandaat gold overigens, via de 
toepassingsverklaring van de INSOLAD-regels voor beoogd curatoren, ${ }^{10}$ in de pre-pack van CDM voor de beoogd curator. Artikel 4 lid 1 INSOLAD-regels bepaalt namelijk: 'de beoogd curator bevordert dat de schuldenaar nagaat of deze over voldoende middelen of financiering beschikt om de bedrijfsvoering voort te kunnen zetten zonder derden (waaronder de fiscus) schade te berokkenen'. Hieruit kan worden afgeleid dat de pre-pack niet bedoeld is voor schuldenaren die hun faillietverklaring nog even uitstellen en nog nieuwe betalingsverplichtingen tijdens de pre-packfase aangaan waarvan op dat moment al duidelijk is dat die niet zullen kunnen worden voldaan. Een beoogd curator die tijdens de prepackfase bemerkt dat er niet genoeg financiële middelen voorhanden zijn, dient zijn taak neer te leggen.

\section{De spelregels en enkele suggesties}

Terug naar de kern van mijn bijdrage. Bij spelregels voor de toepassing van de pre-pack in Curaçao denk ik aan criteria voor toewijzing, de rol van de beoogd curator en verantwoording na faillissement door de curator (voorheen beoogd curator) over de pre-packfase.

\subsection{Criteria voor toewijzing}

Het vertrekpunt hierbij is in de eerste plaats, dat de rechtvaardiging voor toepassing van de pre-pack steeds daarin gelegen moet zijn dat de overtuiging bestaat dat een onderneming een dusdanig maatschappelijk belang vertegenwoordigt, dat haar deconfiture koste wat kost moet worden voorkomen. Het redden van de onderneming is als het ware een belang van hogere orde waaraan het gebrek aan een wettelijke regeling voor pre-packs ondergeschikt mag worden gemaakt. Het maatschappelijk belang zal bijvoorbeeld kunnen blijken uit de sector waarin de onderneming opereert of de omvang van het personeelsbestand. Naast het feit dat dient te worden aangetoond dat er sprake is van een maatschappelijk belang welke de toepassing van een pre-pack rechtvaardigt, dient de schuldenaar ook aannemelijk te maken dat het belang van de gezamenlijke schuldeisers met een pre-pack is gediend. Er dient dus sprake te zijn van zowel een maatschappelijk belang als een belang van de gezamenlijke schuldeisers. Een verzoek tot toepassing van de pre-pack dat is ingegeven door louter belangen van maatschappelijke aard, lijkt mij slechts mogelijk indien die belangen voldoende zwaarwegend zijn en tevens aannemelijk is dat de schuldenaar zijn gedurende de pre-packfase ontstane verplichtingen zal kunnen nakomen.

Ten slotte dient de schuldenaar mijns inziens aan te tonen dat bij een faillissement, zonder voorafgaande pre-packfase, extra waardeverlies optreedt. Bijvoorbeeld omdat belangrijke leveranciers, afnemers en werknemers na een faillissement vrijwel onmiddellijk zullen weglopen.

Indien niet aan de criteria voor toewijzing kan worden voldaan, dient voor de klassieke variant van de doorstart te worden gekozen. Een doorstart vanuit faillissement (zonder voorafgaande pre-packfase) dus. 
Daarnaast zal een verzoek tot toepassing van de pre-pack in ieder geval vergezeld moeten gaan van de volgende informatie:

- $\quad$ een beschrijving van de aard en omvang van de financiële moeilijkheden;

- de meest recente financiële gegevens van de onderneming;

- omschrijving van de exacte reden van de aanvraag (i.e. evident maatschappelijk belang, belang van de gezamenlijke schuldeisers en gegronde vrees waardeverlies);

- de omvang van het personeelsbestand en het aantal arbeidsplaatsen dat naar verwachting behouden zal kunnen blijven;

- een plan van aanpak voor de periode van de pre-pack, inclusief liquiditeitsbegroting waaruit de conclusie kan worden getrokken dat de schuldenaar nog in staat is om zijn lopende verplichtingen en de verplichtingen die tijdens de pre-packfase zullen ontstaan, te voldoen, inclusief het salaris van de beoogd curator;

- een beschrijving van de marktpositie van de onderneming;

- waarderingsrapporten van de activa van de onderneming;

- eventuele partijen waarmee reeds wordt gesproken over de overname van de ondernemingsactiviteiten dan wel de namen van partijen die zullen worden benaderd voor een overname van de ondernemingsactiviteiten; en

- de duur waarvoor de pre-pack wordt verzocht.

De essentie is dat de schuldenaar reeds serieus werk heeft gemaakt van de doorstart alvorens een verzoek tot toepassing van de pre-pack wordt ingediend. Dit om te voorkomen dat de termijn van de pre-packfase onredelijk lang wordt. Een pre-pack dient zodanig goed te zijn voorbereid dat bij het verzoek tot toepassing van de pre-pack een termijn tussen de vijftien en dertig dagen als duur van de pre-packfase kan worden verzocht door de schuldenaar, waarbij het gerecht eventueel de termijn zou kunnen verlengen met maximaal twintig dagen.

Uit een door Hurenkamp uitgevoerde analyse van 48 faillissementsverslagen waarin vóór de faillietverklaring de aanwijzing van een beoogd curator plaatsvond in de periode 1 januari 2012-1 juli 2014, blijkt dat in Nederland gedurende die periode de gemiddelde duur van de pre-packfase 12,5 dagen bedroeg. ${ }^{11}$ De pre-packfase van CDM heeft, afgezet tegen de gemiddelde duur van de pre-packs in Nederland gedurende genoemde periode, erg lang geduurd, namelijk ruim vier maanden.

Gestreefd moet worden naar een zo kort mogelijke duur van de pre-packfase. Dit heeft alles te maken met de gedachte die achter de toepassing van de pre-pack schuilgaat, namelijk het voorkomen van extra waardeverlies doordat de voorbereiding van een doorstart in alle stilte gebeurt zonder dat de beoogd curator geplaagd wordt door onrustige crediteuren. In de praktijk is het, zeker in een kleine gemeenschap als Curaçao, lastig om gedurende langere tijd de pre-pack vertrouwelijk en de crediteuren bijgevolg rustig te houden. En juist die relatieve rust wordt steevast als een belangrijk voordeel van een pre-pack genoemd, vergeleken met de hectiek van de eerste weken van een faillissement.

11 J.R. Hurenkamp, 'Failliet of fast forward? Een analyse van de pre-pack in de praktijk', Tijdschrift voor Insolventierecht 2015/20. 
Niets belet een crediteur om tijdens de pre-packfase het faillissement van de schuldenaar aan te vragen. Ingevolge artikel 4 FB moet een verzoek tot faillietverklaring met den meesten spoed worden behandeld. In de praktijk vindt de behandeling van een verzoek tot faillietverklaring binnen een periode van twee weken na indiening van een dergelijk verzoek plaats. Het is moeilijk voorstelbaar dat de behandeling van een faillissementsverzoek plaats zal kunnen vinden zonder dat bekend wordt gemaakt dat er sprake is van een pre-pack. Het voordeel van de pre-pack wordt daarmee tenietgedaan.

Daarnaast geldt dat naarmate de tijd vordert, het risico voor de schuldenaar dat hij niet meer aan zijn verplichtingen zal kunnen voldoen, en daarmee aansprakelijkheid op grond van de Beklamel-norm, steeds groter wordt. Zoals ik hiervoor al heb betoogd, dient een beoogd curator die vaststelt dat verplichtingen jegens crediteuren niet kunnen worden nagekomen, zijn taak neer te leggen, hetgeen tevens het einde van de pre-pack zal betekenen. Een lange pre-packfase is dus niet zonder risico's.

\subsection{De rol van de beoogd curator}

Het vertrekpunt hierbij is dat vanwege het stille karakter van de pre-packfase schuldeisers niet bij machte zijn om hun belangen te behartigen, waardoor de beoogd curator moet worden beschouwd als de enige hoeder van het belang van de gezamenlijke schuldeisers. Het belang van de gezamenlijke schuldeisers is in de regel gelegen in een zo hoog mogelijke opbrengst van de activa die in het kader van de doorstart (na een voorafgaande prepack) aan de doorstarter worden overgedragen.

Uit de beschikking in het faillissement van $\mathrm{CDM}^{12}$ blijkt dat onder meer als voorwaarde voor inwilliging van het pre-packverzoek is gesteld dat de beoogd curator zo veel mogelijk de INSOLAD-regels voor beoogd curatoren diende te volgen.

De INSOLAD-regels bepalen uitdrukkelijk dat de beoogd curator geen adviseur is van de schuldenaar, geen formele positie bekleedt binnen de onderneming van de schuldenaar en zich laat informeren met het oog op een eventuele toekomstige rol als bewindvoerder of curator van de schuldenaar. Hij laat zich daarbij leiden door de belangen van de gezamenlijke crediteuren en houdt daarbij ook rekening met maatschappelijke belangen, waaronder de werkgelegenheid. Zo nodig geeft hij met het oog op die belangen aanwijzingen aan de schuldenaar over te verrichten handelingen of een te volgen gedragslijn. De beoogd curator is niet gehouden instructies van de schuldenaar op te volgen en bewaart te allen tijde zijn onafhankelijkheid.

De INSOLAD-regels zijn duidelijk ten aanzien van de vraag wat van een beoogd curator wordt verwacht en dienen wat mij betreft richtinggevend te zijn bij het ontwerpen van Curaçaose pre-packrichtlijnen.

Er moet naar mijn mening over één belangrijke vraag wel duidelijkheid bestaan. Aan het feit dat de beoogd curator bij zijn taakuitoefening ook rekening dient te houden met maatschappelijke belangen, waaronder de werkgelegenheid, kleeft de gedachte dat de taak van

12 De beschikking in het faillissement van CDM d.d. 2 februari 2017, E.J. no. F. 81849/2017, ECLI:NL:OGEAC: 2017:7. 
de beoogd curator ruimer wordt gezien dan alleen het behartigen van de belangen van de gezamenlijke schuldeisers. Dit is op zich een goede gedachte, maar de vraag die opkomt is of bij een confrontatie tussen het belang van de gezamenlijke schuldeisers met andere belangen, het belang van de gezamenlijke schuldeisers altijd zal moeten prevaleren.

Uit jurisprudentie van de Hoge Raad inzake de persoonlijke aansprakelijkheid van een curator, lijkt in ieder geval slechts de conclusie getrokken te kunnen worden dat de curator bij de uitoefening van zijn taak belangen van maatschappelijke aard mag laten meewegen en niet dat hij (onder omstandigheden) de plicht heeft belangen van maatschappelijke aard te laten prevaleren boven het belang van de gezamenlijke schuldeisers. ${ }^{13}$ Het uitgangspunt zal daarom moeten zijn dat de belangen van de gezamenlijke schuldeisers in de regel zullen moeten prevaleren, met als uitzondering de situatie waarbij het belang van de gezamenlijke schuldeisers dat in geding is, niet in verhouding staat met de maatschappelijke belangen die dreigen te worden geschaad.

Een beoogd curator die na aanvang van de pre-packfase vaststelt dat met een pre-pack louter maatschappelijke belangen worden gediend, zonder dat er tevens sprake is van voornoemde uitzondering, zal mijns inziens zijn taak moeten neerleggen.

Mijn suggestie is dat bij zijn aanstelling een beoogd curator in ieder geval de volgende opdrachten meekrijgt:

- De beoogd curator moet zich in beginsel altijd laten leiden door de belangen van de gezamenlijke schuldeisers, met als uitzondering de situatie waarbij het belang van de gezamenlijke schuldeisers dat in geding is, niet in verhouding staat met de maatschappelijke belangen die dreigen te worden geschaad.

- De beoogd curator controleert de stappen die de schuldenaar voorafgaand aan de prepackfase reeds heeft genomen en volgt kritisch de vervolgstappen.

- De beoogd curator dient een eigen onderzoek te verrichten naar de waarde van het bod van de kandidaat-koper.

- Indien na zijn aanstelling blijkt dat er reeds onderhandeld wordt met één overgebleven kandidaat-koper, doet de beoogd curator, indien hiertoe aanleiding bestaat, zelfstandig een marktverkenningsonderzoek naar de interesse van derden. ${ }^{14}$ Indien de overgebleven kandidaat-koper gelieerd is aan de schuldenaar, moet de beoogd curator altijd een marktverkenningsonderzoek naar de interesse van derden doen.

\subsection{Verantwoording}

In de verslaglegging over zijn werkzaamheden in de pre-packfase dient tot uitdrukking te komen dat de beoogd curator zich tot het uiterste heeft ingespannen om de belangen van de gezamenlijke schuldeisers te behartigen (i.e. zo hoog mogelijke opbrengst van de te verkopen activa).

13 Zie HR 24 februari 1996, NJ 1996/, 472 (Sigmacon II), HR 19 april 1996, NJ 1996, 727 (Maclou) en HR 19 december 2003, RvdW 2004/8 (Mobell/Interplan).

14 De aanleiding kan gelegen zijn in het feit dat het onderzoek van de beoogd curator naar de stappen voorafgaand aan de pre-pack fase weinig duidelijkheid verschaft over het biedingsproces dat heeft plaatsgevonden. 
Het verdient aanbeveling de beoogd curator in ieder geval de volgende zaken te laten beschrijven in zijn eerste faillissementsverslag:

- de toestand van de onderneming zoals hij deze aantrof bij zijn aanstelling als beoogd curator;

- de reden waarom de doorstart niet vanuit faillissement heeft plaatsgevonden;

- het door hem tijdens de pre-packfase zelfstandig gedane onderzoek naar de waarde van het bod van de kandidaat-koper;

- de resultaten van een eventueel marktverkenningsonderzoek; en

- het verkoopproces, en de (gemotiveerde) keuze voor de overnamekandidaat. 